IOS Press

\title{
Effect of introductions of a predator complex on spider mites and thrips in a tunnel and an open field of pesticide-free everbearer strawberry
}

\author{
Tuomo Tuovinen* and Isa Lindqvist \\ MTT Agrifood Research Finland, FI-31600 Jokioinen, Finland
}

Submitted 17 June 2014; accepted 27 August 2014

\begin{abstract}
.
BACKGROUND: Chemical control of spider mites and thrips in everbearer strawberry is difficult as few efficient chemicals are available and residues represent a risk. In the north the success of biocontrol of mites and thrips in open fields compared with tunnels needs to be evaluated.

OBJECTIVES: To investigate the need for control of spider mites and thrips and evaluate the effectiveness of biological control agents in everbearer strawberry.

METHODS: Similar experimental plots, in a tunnel and an open field, planted with three everbearer strawberry varieties were arranged to compare the effect of introductions of the spider mite predator Phytoseiulus persimilis and releases of the generalist predatory mites Neoseiulus cucumeris and Neoseiulus barkeri and a predatory bug, Orius majusculus. Several sampling methods were used to evaluate mite and thrips populations.

RESULTS: Phytoseiulus persimilis was successful against spider mites. Naturally occurring cecidomyiid and staphylinid predators affected control positively. Thrips damage remained mostly tolerable. The dominant thrips species were Thrips major, Thrips atratus, Thrips vulgatissimus and Frankliniella intonsa. Thrips numbers in the beating tray samples correlated with thrips damage to berries.

CONCLUSIONS: Predatory mites were effective in controlling spider mites in an open field and a tunnel. The need for thrips control depended on the strawberry variety. Naturally occurring predators contributed to the control of spider mites and thrips.
\end{abstract}

Keywords: Everbearer strawberry, biological control agents, Phytoseiulus persimilis, Neoseiulus barkeri, Neoseiulus cucumeris, Orius majusculus, two-spotted spider mite, thrips

\section{Introduction}

The two-spotted spider mite (TSSM) Tetranychus urticae Koch (Acari: Tetranychidae) is one of the main pests of strawberry Fragaria x ananassa Duchesne in temperate areas, especially in protected cultivation but also under field conditions [1]. In northern latitudes like Finland, TSSM is considered to be a less important pest, which in open fields can reach harmful levels only in dry and warm seasons. However, during the last decade higher TSSM populations have become more common and growers need to reconsider pest management options [2]. Although the economic damage level of TSSM is fairly high, tens of mites per leaflet [3], this level can be reached in a few weeks under favorable weather conditions in June-July in Finland. In practice, the use of pyrethroid insecticides before flowering

\footnotetext{
${ }^{*}$ Corresponding author: T. Tuovinen, MTT Agrifood Research Finland, FI-31600 Jokioinen, Finland. Tel.: +358 40 5110891; E-mail: tuomo.tuovinen@mtt.fi.
} 
has promoted a rapid TSSM increase later in mid-summer. The increasing tendency to grow strawberries in walk-in polythene tunnels will allow rapid TSSM population growth already during the first weeks of the season, leading to increased risk of yield losses [3]. Biological control by releasing predatory mites such as Phytoseiulus persimilis Athias-Henriot (Acari: Phytoseiidae) and Neoseiulus californicus (McGregor) has proven successful for protected strawberry [4], but experiments under open field conditions are few for the Nordic countries. Other predatory mite species, Neoseiulus cucumeris (Oudemans) and Neoseiulus barkeri Hughes, have been used to control the strawberry tarsonemid mite Phytonemus pallidus ssp. fragariae (Zimmerman) satisfactorily in field-grown strawberries in Finland [5]. Both species were also tested in greenhouse-grown strawberry against the strawberry tarsonemid mite and TSSM, but did not control TSSM satisfactorily [6].

Thrips have been considered to be minor pests of field-grown strawberry in Finland, and suspected injuries were rarely reported until the 2000s. However, the damage was not confirmed to be exclusively caused by thrips feeding, but also other physical factors may have been involved, as discussed by Koike et al. [7]. As the main thrips species causing damage to strawberry in Europe, the western flower thrips, Frankliniella occidentalis (Pergande) [8, 9], is known to occur only in greenhouses in Finland, other species must cause the putative thrips damage in open fields and tunnel-grown strawberries, but the species that damage strawberry in Finland are not known. The predatory mites $N$. cucumeris and $N$. barkeri have been used for biocontrol, and the former is currently used in greenhouses against thrips [10]. Both species also controlled tarsonemid mites in greenhouse-grown strawberries [6]. The anthocorid bug species Orius laevigatus (Fieber) and Orius majusculus (Reuter) (Heteroptera: Anthocoridae) are currently used for thrips control of greenhouse-grown vegetables in Finland (Heini Koskula, pers. comm.), but no biocontrol agents have been used or studied for strawberries grown in open fields or tunnels.

Remontant or everbearer strawberries are not widely grown in Finland because of lack of adequate horticultural knowledge and paucity of suitable varieties. In everbearer strawberry varieties only pesticides with a very short waiting period can be used during harvesting, even though they are allowed for flowering plants, and therefore biological control methods are more needed than for normal June-bearing varieties. The interest in using biological control methods to control mites is increasing also for June-bearing varieties because there are fewer efficient pesticides available due to increasing demands to minimize their environmental impacts. However, reduced use of pesticides could enhance naturally occurring predators and parasitoids and hence back-up the direct biological pest control [8, 11].

This experiment represents part of the investigations on possibilities for everbearer strawberry cultivation in Finland in 2007-2009. The damage caused by various insects, diseases and other factors in everbearer strawberry varieties in tunnels and open fields was reported earlier [12]. The aim of this report is to indicate the effectiveness and compare the biological control of spider mites and thrips in three strawberry varieties in a walk-in polythene tunnel and an open field. As no pesticides were used in the experimental field the naturally occurring predators were able to colonize strawberries if attractive prey populations developed. Two different strategies were applied for TSSM control by $P$. persimilis: inundative releases at a relatively high initial population in 2008 and one inoculative release at a lower initial population in 2009. At the same time thrips control was carried out by releasing two generalist predatory mite species and a predatory bug species.

\section{Materials and methods}

\subsection{Experimental field}

The experimental field was prepared at MTT Agrifood Research Finland, Jokioinen $\left(60^{\circ} 48^{\prime} \mathrm{N}, 23^{\circ} 28^{\prime}\right.$ E) in autumn 2007. The field had been fallow for a few years and necessary weed control with glyphosate was carried out and composted horse manure spread on the field as soil enrichment prior to mulching. Two areas, each $10 \times 50$ $\mathrm{m}$, were divided into three rows and were mulched with black plastic and drip irrigation hoses were installed in each row.

In spring 2008 a polythene tunnel $(6 \times 30 \mathrm{~m}, 3.5 \mathrm{~m}$ high $)$ was built in one of the areas and the other similar area was left without protection. The experimental design was identical in the two areas: each row was divided into two main blocks, including three $4 \mathrm{~m}$ long plots (25 plants/plot) of each variety, resulting in six replicates by variety. Plots were separated by a $1 \mathrm{~m}$ buffer zone of three wild strawberry, Fragaria vesca L., plants. 


\subsection{Plants}

In May 2008 strawberry plants of three everbearer strawberry varieties Rita, Rondo (Norway) and Malling Opal (UK), propagated at MTT Horticulture, were planted. The varieties were randomized in the plots in each row in the blocks to give 900 plants in 36 plots, plus the buffer zones of three wild strawberry plants.

The field was fertilized and watered by drip irrigation. In the open field, immediately after planting, the strawberries were temporarily protected with gauze from frost over several nights. The polythene tunnel cover was removed in November, and double gauze was spread over both areas to protect the strawberry plants from low temperatures during the winter.

In spring 2009 the removal of the gauze revealed large-scale damage (over 50\%) by field voles, Microtus agrestis L. As a consequence, all plants in the field had to be replaced with a new set of plants raised by MTT Horticulture. Before planting, all plants of the variety Malling Opal were treated with fosetyl-aluminium against crown rot, Phytophthora cactorum (Leb. \& Cohn) Schroet., which in the previous year destroyed some plants in the experimental field.

The grass in the row alleys was regularly mowed and the rows were weeded. Runners were removed and carried off from the field several times during the 2009 season, but not in 2008.

\subsection{Measurements}

During the growing season temperature and rainfall in the open field were measured by the local weather station, located one $\mathrm{km}$ from the field (Fig. 1). Temperature and humidity in both areas were recorded using a datalogger (WKO-57 usb-datalogger) at the level of the vegetation. Soil moisture was measured once a week, at $15 \mathrm{~cm}$ depth, using a digital TM-93 tensiometer (Niewkoop, Holland).

\subsection{Sampling mites and insects}

Leaf sampling for TSSM and predatory mites and insects was carried out in two ways, by variety and by plot, followed by leaf washing and microscopic investigation. Sampling by variety was started after planting in June, followed by similar samplings at six-week intervals in 2008 and four-week intervals in 2009. Each sample consisted of six randomly selected open leaves per plot, in total 60 leaves per variety in both areas. The leaf samples were weighed before washing. The leaves were put in warm water $\left(+40^{\circ} \mathrm{C}\right)$ with $1-2 \%$ detergent for at least one hour and then rinsed through a $0.063 \mathrm{~mm}$ sieve. The remaining sample with mites and insects was then collected from the sieve by rinsing the sample with $70 \%$ ethanol into bottles and stored for counting mites. Spider mites, phytoseiid mites (P. persimilis), cecidomyiid and staphylinid larvae and other insects were identified either using a binocular microscope or later from mounted slides (other phytoseiid species).

The parallel sampling by plot for direct counting of mites was started when the first TSSM were recorded in the washing samples, and continued at 3-4 week (2008) or two week (2009) intervals. One middle leaflet was selected
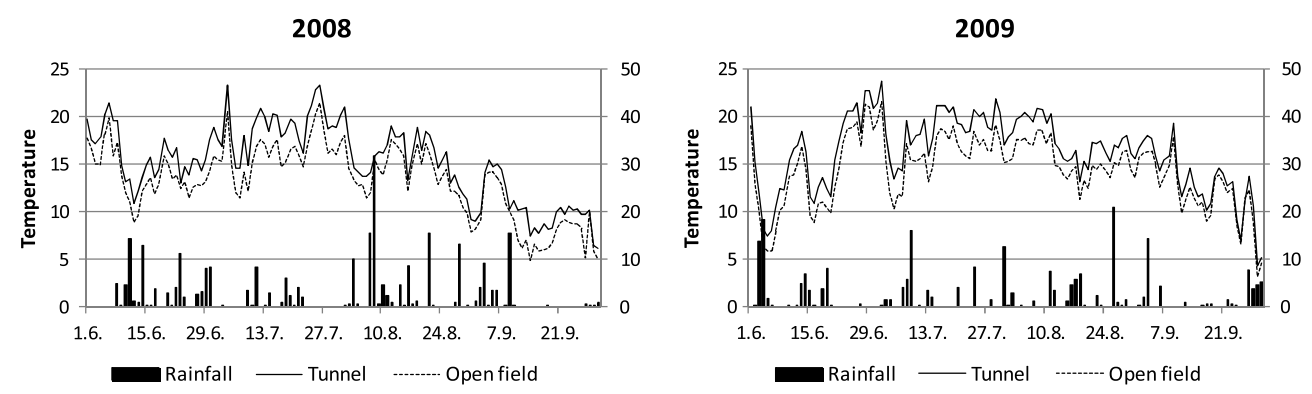

Fig. 1. Weather records for June-September 2008-2009. Mean temperatures were in $200815.2^{\circ} \mathrm{C}$ and $13.2^{\circ} \mathrm{C}$, in $200916.1^{\circ} \mathrm{C}$ and $14.2^{\circ} \mathrm{C}$ in the tunnel (solid line) and in the open field (broken line), respectively. Precipitation (bars) was $268 \mathrm{~mm}$ in 2008 and $226 \mathrm{~mm}$ in 2009 (in June-August 2008: $228 \mathrm{~mm}, 2009: 180 \mathrm{~mm}$ ). 
from five randomly chosen plants per plot. The leaflet samples were weighed before inspection and preliminary identification under a binocular. TSSM and predatory mites and their eggs were counted and the predatory mites were preserved for later identification. Thrips and other insects were counted and predatory species were identified.

In 2009 the first leaf sampling by plot was made in mid-June. The development of the spider mite population in the buffer zone plants was monitored by taking a leaflet from one or two plants per buffer zone with three or six plants, respectively.

\subsection{Monitoring thrips}

Yellow and blue glue traps (size in 2008: $190 \times 270 \mathrm{~mm}$, in 2009: $95 \times 270 \mathrm{~mm}$, as cylinders, Silvandersson, SE), two of each colour, were placed in both experimental areas above the plants to catch thrips and other flying insects. The traps were changed once a week and then stored in the freezer. Thrips were counted but not identified to species level. In addition to these traps, one-day traps were set up in both fields in 2009 , for comparison of daily and weekly catches.

Strawberry flowers were sampled for thrips once in 2008 and three times in 2009. One flower from each of ten randomly chosen plants per plot per variety was shaken directly in a bottle of $70 \%$ alcohol. The number of thrips was counted under a binocular and the adult specimens were preserved for identification. Thrips were also evident in leaf and leaflet samples for mites.

In addition to targeted sampling of thrips, beating samples were collected in order to monitor other insects, e.g. anthocorid bugs and the strawberry blossom weevil Anthonomus rubi Herbst. We used a wash basin from which one third was removed so that the basin was easy to set under the foliage and flower trusses which were quickly shaken over the basin [13]. Samples were collected from five plants per plot and insects were readily classified by orders or families. These samples also contained thrips, which were counted but not identified to species level. In 2008, the first samples were returned to the plants to avoid affecting the numbers of anthocorid bugs.

Thrips were also collected from several weed species growing inside the experimental area in order to compare the species composition on weeds and strawberry plants. Sampling was performed in late August in 2008 and the adult specimens were identified.

\subsection{Biocontrol measures}

To control TSSM the predatory mite Phytoseiulus persimilis (Biotus Ltd., FI) was introduced in both years. In 2008, 26 mites/plant were spread evenly by hand directly from bottles on all plants in the tunnel, but not in the open-field, divided into five introductions from mid-July till the end of August. In 2009, P. persimilis (4/plant) was introduced only once, both in the tunnel and in the open field, at the beginning of July (Table 1).

In both years basic thrips control was carried out by introductions of $N$. cucumeris and $N$. barkeri (Biotus Ltd.). In 2008 N. cucumeris (25/plant) were spread both in the tunnel and in the open field. Thrips control was complemented

Table 1

Dates and amounts of biocontrol agent introductions. No. of released predators/plant

\begin{tabular}{|c|c|c|c|c|c|c|c|c|c|}
\hline & 2008 & & & & & & 2009 & & \\
\hline Tunnel & 26.6 . & 17.7 . & 24.7. & 6.8. & 13.8. & 20.8 . & 27.8 . & 23.6. & 8.7 \\
\hline O. majusculus & 2 & - & - & - & - & - & - & - & - \\
\hline N. barkeri & - & - & 100 & - & - & - & - & 25 & - \\
\hline N. cucumeris & 25 & - & - & - & - & - & - & 25 & - \\
\hline P. persimilis & - & 6 & - & 8 & 4 & 4 & 4 & - & 4 \\
\hline \multicolumn{10}{|l|}{ Open field } \\
\hline O. majusculus & 3 & - & - & - & - & - & - & - & - \\
\hline N. barkeri & - & - & - & - & - & - & - & 25 & - \\
\hline N. cucumeris & 25 & - & - & - & - & - & - & 25 & - \\
\hline P. persimilis & - & - & - & - & - & - & - & - & 4 \\
\hline
\end{tabular}


with a simultaneous introduction of Orius majusculus (Reuter) (Hemiptera: Anthocoridae) (Biotus Ltd.) pre-adult stages (2-3 bugs/plant) in both experimental areas. Later in July N. barkeri (100/plant) was introduced only in the tunnel. In 2009, a mixture of $N$. cucumeris and $N$. barkeri (25/plant each), was spread once in both fields (Table 1).

\subsection{Harvesting}

Harvesting began as soon as the first berries ripened, the last week in June in the tunnel and a week later in the open field in 2008 and in 2009 in mid-July in both areas. Harvesting was continued twice a week until the frosty nights at the end of September. All ripe berries in each plot were picked. After picking, all berries were sorted into marketable and non-marketable categories, counted and weighed. In the latter category berries were also inspected singly and sorted according to the damage caused by named pests, diseases or other factors. The berries in all categories were then counted and weighed.

\subsection{Statistical analyses}

For statistical analyses the number of TSSM per gram fresh leaf was used instead of per leaf or leaflet counts to diminish the effect of varying leaf/leaflet size (Table 2). Kruskal-Wallis ANOVA on ranks and a pairwise multiple comparison (Dunn's method) were used if distribution was not normal even after $\log (\mathrm{x}+1)$ transformation. Normally distributed data were tested using ANOVA and a multiple pairwise procedure (Holm-Sidak) or Tukey's test to establish the statistically significant differences among mean values in TSSM numbers in protected and open-field strawberry and three everbearer varieties (SigmaPlot 12). The same procedures were used for predators found on the leaf samples. Thrips numbers in the flowers and beating tray samples, and recorded thrips damage assessments, were compared using Pearson correlation for pooled data.

\section{Results}

\subsection{Two-spotted spider mite}

The TSSM data obtained from wash samples for the whole leaves or direct inspection of the leaflets were converted into numbers of mites per gram of fresh leaf, which was considered to reflect the damage level better than per leaf numbers. Means for the whole leaf sample weights are given in Table 2. Overall leaf weight of cv. Rondo and cv. Malling Opal was higher than that of cv. Rita both in the tunnel and in the open field.

In 2008 the first sampling after planting in mid-June revealed very low densities of TSSM both in the tunnel and open field. The first introduction of $P$. persimilis was made after the second wash sample in mid-July when there were higher motile TSSM numbers, as well as eggs, in the tunnel compared with only a slight increase in the open field $(\mathrm{F}=142.8, P<0.001)$ (Fig. 2). Two weeks later TSSM numbers in Rondo and Malling Opal dropped whereas in Rita the population continued to grow. The earlier (26 June) introductions of $N$. cucumeris and $O$. majusculus aimed at

Table 2

Fresh leaf weights (g/leaf) of the wash samples used to convert leaf and leaflet sample data in 2008 and 2009

\begin{tabular}{lllllllll}
\hline & & 2008 & & & 2009 & & & \\
& & 16.6. & 31.7 & 11.9. & 24.6. & 22.7. & 25.8. & 24.9. \\
\hline \multirow{2}{*}{ Tunnel } & M. Opal & 2.13 & 1.73 & 1.23 & 0.84 & 1.43 & 1.39 & 1.04 \\
& Rita & 1.39 & 1.11 & 0.84 & 0.57 & 1.21 & 0.97 & 0.91 \\
& Rondo & 2.42 & 1.86 & 1.36 & 0.81 & 1.9 & 1.74 & 1.44 \\
& M. Opal & 1.35 & 1.93 & 1.48 & 0.79 & 1.96 & 1.5 & 1.79 \\
& Rita & 0.87 & 1.52 & 1.14 & 0.58 & 1.71 & 1.21 & 1.22 \\
& Rondo & 1.43 & 2.03 & 1.71 & 0.74 & 2.01 & 2.3 & 1.88 \\
\hline
\end{tabular}



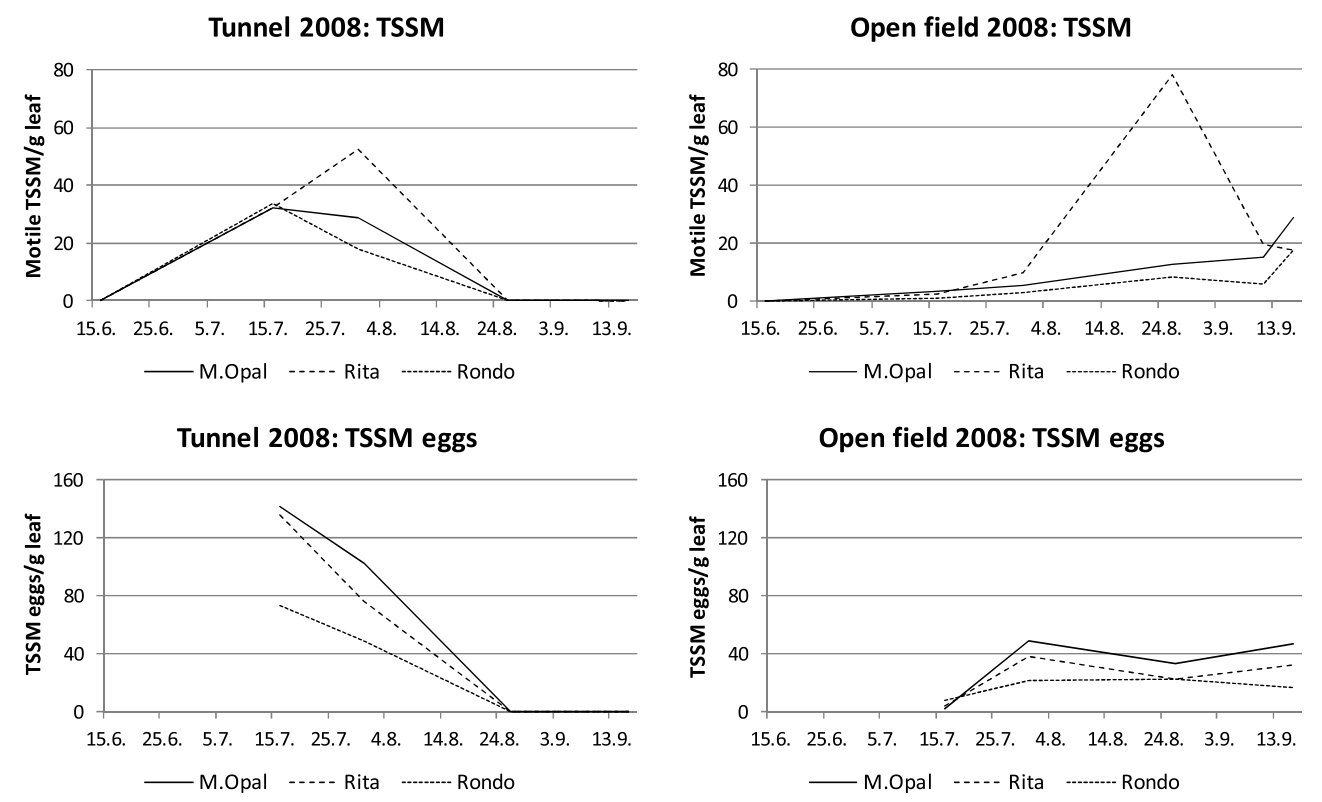

Fig. 2. Motile two-spotted spider mites and eggs per gram fresh leaf, combined data from wash and leaflet sampling in 2008.

thrips control did not have any noticeable immediate effect on TSSM numbers in the tunnel, whereas in the open field TSSM numbers stayed low until August. Repeated weekly releases of $P$. persimilis in the tunnel were made during August. In late August TSSM disappeared in the tunnel and neither motile nor egg stages were evident at the end of the season. In the open field TSSM numbers remained moderate except for a peak in cv. Rita at the end of August, although not statistically significant $(P=0.058$, Tukey's test), and a slight increase in September. In the tunnel, the overall pooled TSSM and egg number was higher than in the open field $(\mathrm{F}=14.67, P<0.001)$, and in Malling Opal higher than in Rondo ( $t=3.167, P=0.011$, Holm-Sidak method). No significant differences were established in the pooled total numbers for all stages of TSSM inside the areas.

After the new planting in May 2009 the first sampling showed an initial TSSM infestation in Rondo whereas Malling Opal and Rita were practically free of the mites (Fig. 3). The releases of N. cucumeris and N. barkeri in June for thrips control appeared to prevent the TSSM population growth in the tunnel and in the open field. After the introduction of a moderate number of $P$. persimilis in July TSSM numbers stayed very low and the TSSM almost disappeared in the tunnel before the end of the season and did not increase in the open field to reach damaging levels. TSSM egg numbers fluctuated more than the motile mite numbers, but no significant differences between tunnel and open field or varieties were detected. The pooled number of motile TSSM in the open field was higher than in the tunnel $(\mathrm{F}=9.382, P=0.005)$.

\subsection{Thrips}

In 2008 thrips numbers in leaf and leaflet samples were small, maximum values were recorded on 31 July: 0.12 , 0.19 and 0.14 thrips per gram leaf in the tunnel on Malling Opal, Rita and Rondo, respectively. Subsequently only single specimens of thrips were found from leaf and leaflet samples. The flower sampling on 18 July also resulted in small numbers: Malling Opal 0.92/0.32, Rita 0.97/0.32, and Rondo 0.5/0.23 thrips per flower in the tunnel/open field, respectively (single sample per variety, no statistical analyses). As thrips numbers varied considerably in flowers the figures do not exclude the possibility of exceeding damage levels in some of the flowers.

Relatively high numbers of thrips were caught in yellow and blue glue traps compared with those for the beating samples from plants (Figs. 4-5). The largest catches in 2008 were from blue traps at the end of July in the tunnel. In 2009 the peak catches were earlier and highest for blue traps in the open field. In 2008, the total number of thrips 

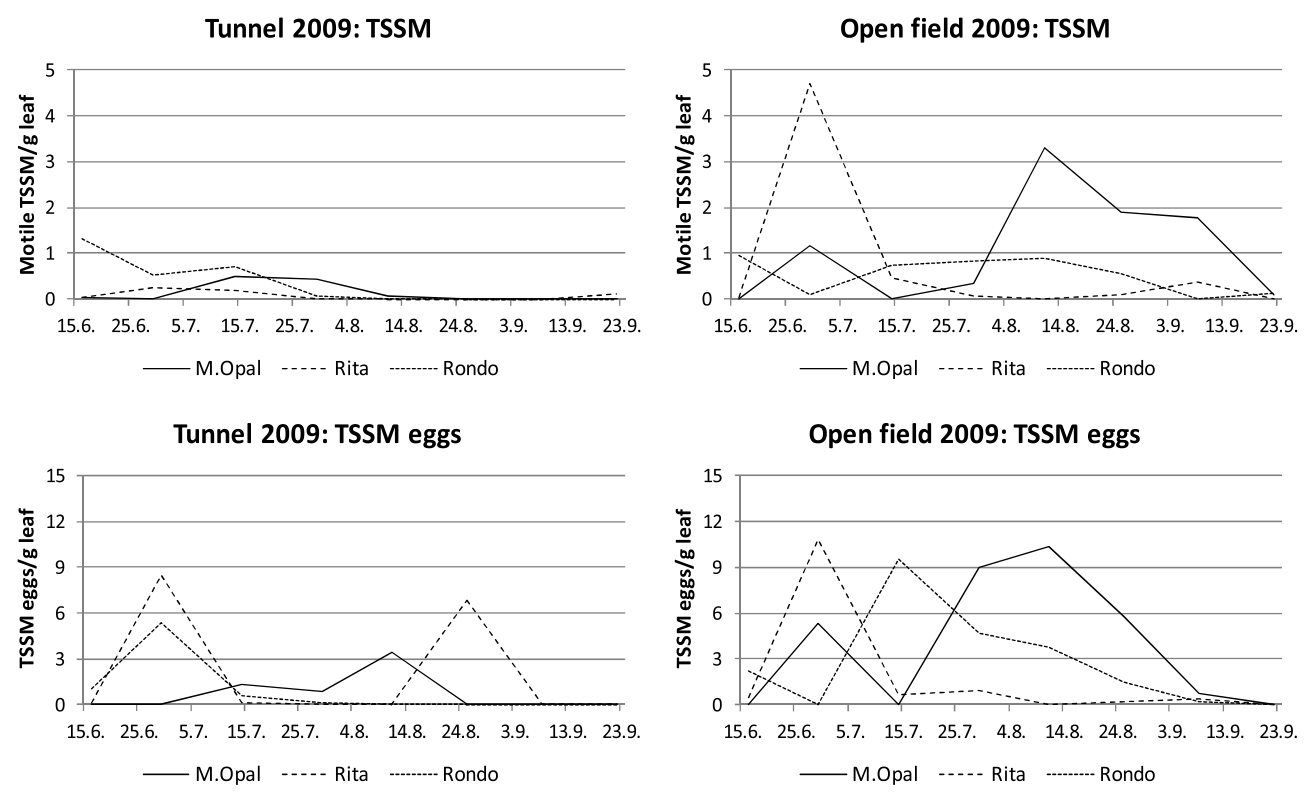

Fig. 3. Motile two-spotted spider mites and eggs per gram fresh leaf, combined data from wash and leaflet sampling in 2009.

in the yellow traps was 1.35 times and in the blue traps 2.47 times higher in the tunnel than in the open field. In 2009 the difference was 1.71 and 1.05 times, respectively. In beating samples, thrips were generally more common in the tunnel in 2008 than in the open field $(\mathrm{F}=124.2, P<0.001)$, and for all strawberry varieties higher numbers of thrips were sampled in the tunnel (Rita and Rondo, $P<0.001$, Malling Opal, $P=0.003$, Holm-Sidak). In the tunnel, thrips were more common on Rita and Rondo than on Malling Opal $(P<0.001)$, whereas in the open field there were no statistically significant differences among varieties. In 2009, thrips were more common in the open field beating samples $(P<0.001)$, and on Rita they were more common than on Malling Opal or Rondo $(P<0.001)$.

In 2009, thrips were scarcer on leaf and leaflet samples, and only few individuals were found. Flower sampling was carried out once a month in July-September. Thrips numbers per flower in the tunnel and open field were 0.92/1.50 for Malling Opal, 1.13/2.47 for Rita and 0.97/0.80 for Rondo, respectively (max. numbers, no statistical analysis).

The quality analyses of the yield revealed significant differences in the percentage thrips damage in both years among varieties (Fig. 6). In 2008, thrips damage symptoms in the tunnel were significantly more evident on Rita than on Rondo $(P=0.006)$ and Malling Opal $(P=0.044)$. In 2009, thrips damage was again more common in the tunnel on Rita than on Rondo or Malling Opal $(P=0.043$ and $P=0.042$, respectively). Damage was also greater in the open field $(P<0.001$, both varieties) than in the tunnel, Rita being again more damaged in the open field than the other two varieties $(P<0.001)$. Generally thrips damage symptoms were quite slight on the ripe berries and the yield losses, even when all symptomatic berries were classified as unmarketable, were bearable except for Rita in the open field in 2008.

Comparison of thrips samples from flowers for a single sampling date and damage symptoms on berries were not significantly correlated in $2008\left(r^{2}=0.103\right.$, Pearson correlation), whereas in 2009, using the pooled data from three samplings, the positive correlation was significant $\left(\mathrm{r}^{2}=0.764, P=0.023\right)$. The overall correlation between the average thrips numbers in beating samples in June-August and the number of damaged berries was statistically significant (2008: $\left.\mathrm{r}^{2}=0.353, P<0.001, n=35 ; 2009: \mathrm{r}^{2}=0.594, P<0.001, n=36\right)$. The correlation was stronger in the open field (2009: $\left.\mathrm{r}^{2}=0.648, P<0.001, n=18\right)$ than in the tunnel $\left(\mathrm{r}^{2}=0.251, P=0.034, n=18\right)$ (Fig. 7). Differences between years were apparent: in 2008 thrips were more common in the tunnel whereas smaller numbers of thrips in the open field caused more severe damage. In 2009, thrips were more common in the open field but damage remained slight. 

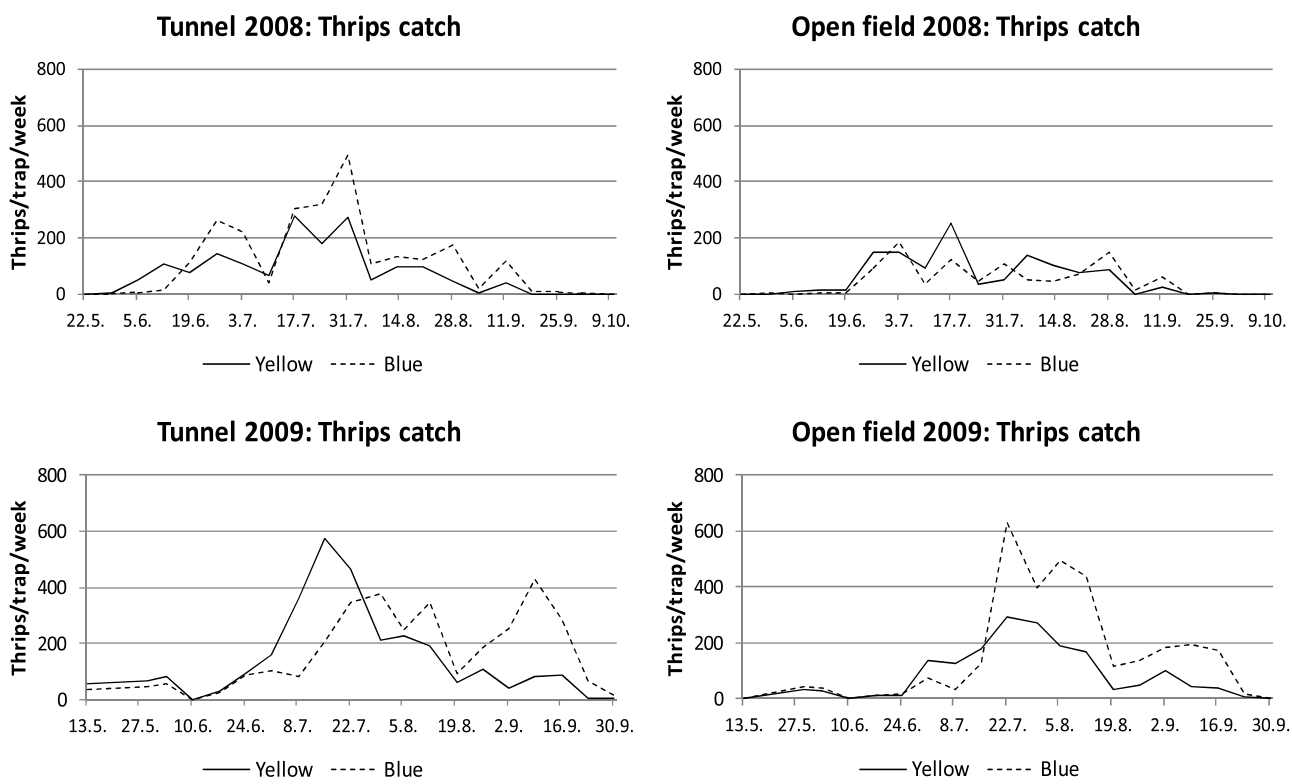

Fig. 4. Monitoring results for thrips using yellow and blue glue traps (cylinder, size in $200819 \times 27 \mathrm{~cm}$, in $20099.5 \times 27 \mathrm{~cm}$, data equalized to smaller trap size).
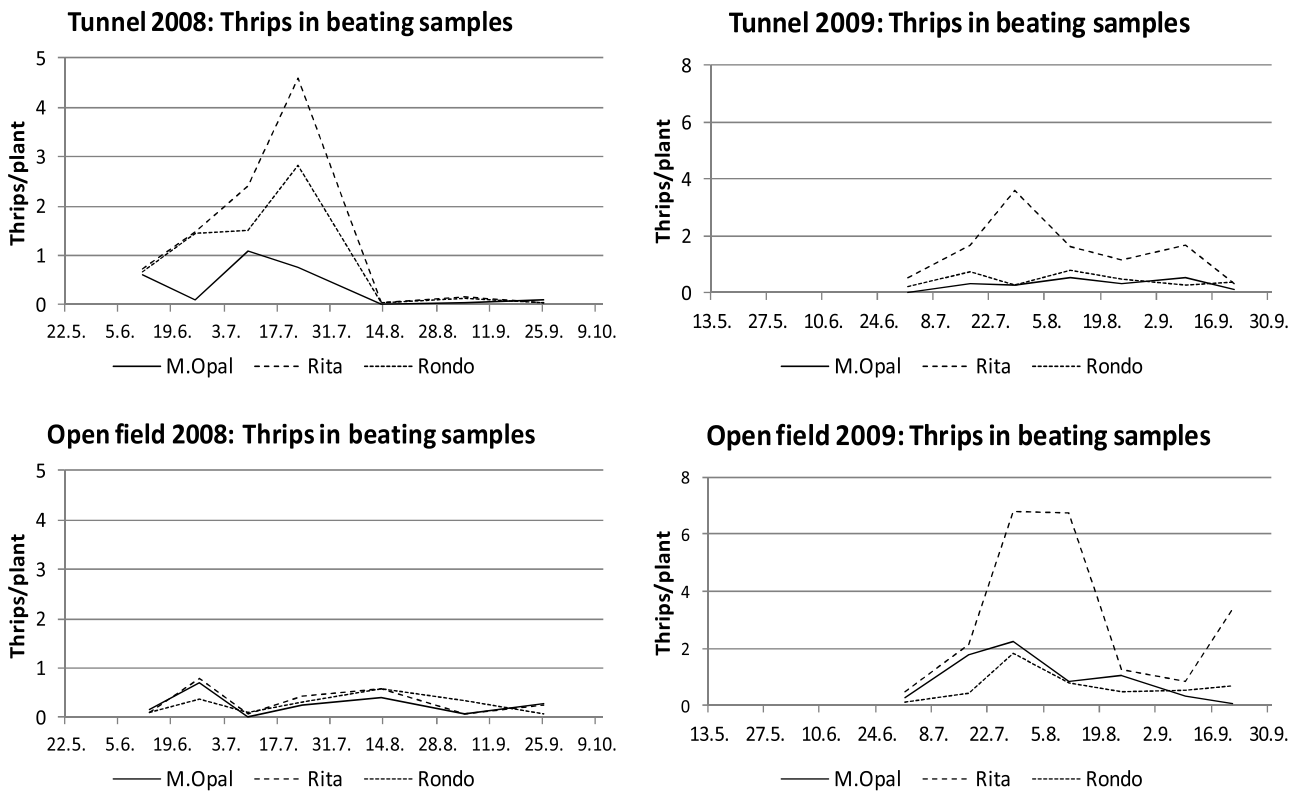

Fig. 5. Monitoring results for thrips by beating tray sampling.

In total eight thrips species were identified from strawberry flowers and three species were present in both years (Table 3). The most common thrips species on strawberry flowers were Thrips major, Thrips atratus, Thrips vulgatissimus and Frankliniella intonsa. The same species were present on various weed species growing in the area (Table 3). 
Thrips damage: 2008

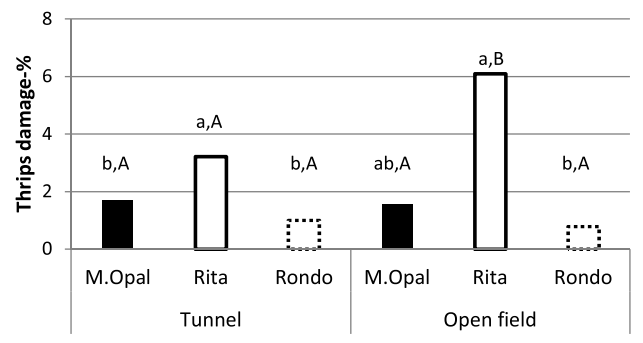

Thrips damage: 2009

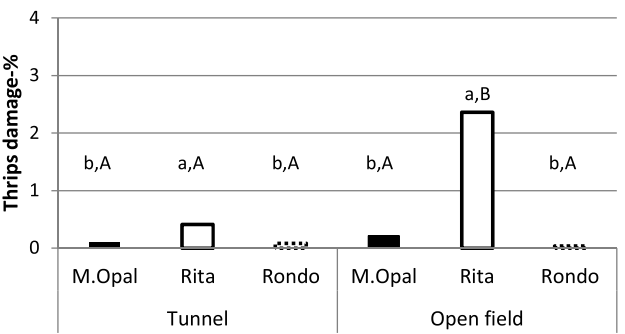

Fig. 6. Thrips damage to yield as a percentage of the total berry weight. Small letters indicate significant differences between cultivars inside the groups (tunnel/open field) and capital letters between the groups. Tukey's test, $P=0.05$.

2008

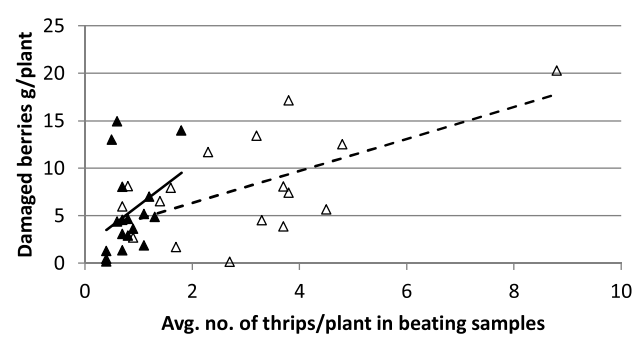

2009

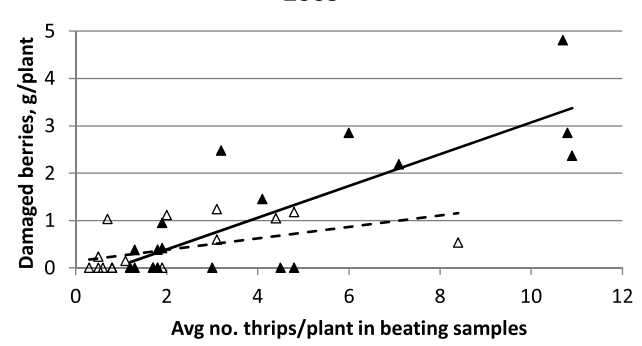

Fig. 7. Correlation between thrips numbers and thrips damage. Open triangles, dashed line: tunnel, filled triangles, solid line: open field.

\subsection{Natural enemies}

The dominating phytoseiid species on leaf samples was P. persimilis both in 2008 and 2009, 53\% and 66\%, respectively, the remainder being largely $N$. cucumeris (Fig. 8). In 2008 in the tunnel $P$. persimilis was almost the only species found throughout the season although $N$. cucumeris was also found after the releases began and in the open field. For the whole leaf samples there was no significant correlation between predatory mite and TSSM numbers $\left(\mathrm{r}^{2}=0.190, P=0.068, N=18\right.$, Spearman Rank Order Correlation). In 2009, the majority of specimens of $P$. persimilis were found two weeks after the introduction in July. In June 2009, before the release of $P$. persimilis, the earlier released $N$. cucumeris and $N$. barkeri were the only species present in the samples. Later in July-August, specimens of the naturally occurring species Neoseiulus (Amblyseius) zwoelferi (Dosse), Neoseiulus (Amblyseius) reductus Wainstein and Proprioseiopsis okanagensis (Chant) and one specimen of Neoseiulus agrestis (Karg) were also present in the samples. N. agrestis had not been recorded earlier in Finland [14-16]. The percentages of the species through the whole 2009 season were P. persimilis $66.4 \%$, N. barkeri $4.6 \%, N$. cucumeris $23.6 \%$, and the four naturally occurring species $5.4 \%$ in total (total $N=241$ ). The correlation between predatory mite and TSSM numbers for whole leaf samples was slight but significant $\left(\mathrm{r}^{2}=0.114, P=0.029\right)$.

Neither the introduced $O$. majusculus nor any other anthocorid bugs were found on leaf or leaflet samples, which was expected as it was unlikely that the fast-moving species were picked up on leaves. In 2008, yellow and blue traps caught only a total of 18 and 6 adult anthocorid bugs in the tunnel and in the open field, respectively. In the last beating samples in August-September 2008 a total of 133 hemipteran bugs were collected of which $17 \%$ were $O$. majusculus, and $10 \%$ Orius niger (Wolff). $82 \%$ of the specimens of O. majusculus were sampled in the open field. In the first samples 106 hemipteran bugs were collected, but they were not identified to species level as the samples were released back on the plants after counting. In 2009, when no introductions of $O$. majusculus were made, 158 hemipteran specimens were collected and only $6 \%$ were the anthocorid bug $O$. niger.

Cecidomyiid and staphylinid larvae were the principal naturally occurring predatory insects on the leaf samples (Fig. 9). In 2008, cecidomyiid larvae were most common on Rita in the tunnel and their numbers peaked at the end of 
Table 3

Thrips species identified in strawberry and in the most common weeds in the experimental area. The dominant species marked by asterisk ( $>25 \%$ of total number; marked only if $>10$ specimens)

\begin{tabular}{|c|c|c|c|}
\hline Plant & Thrips species & 2008 & 2009 \\
\hline Strawberry & Thrips major Uzel * & 20 & 34 \\
\hline \multirow[t]{7}{*}{ Fragaria $x$ ananassa } & Thrips atratus Haliday * & - & 40 \\
\hline & Thrips vulgatissimus Haliday * & 3 & 34 \\
\hline & Frankliniella intonsa (Trybom) * & 12 & 15 \\
\hline & Aeolothrips fasciatus (L.) & 3 & - \\
\hline & Frankliniella tenuicornis (Uzel) & - & 2 \\
\hline & Haplothrips aculeatus (Fabricius) & - & 1 \\
\hline & Haplothrips leucanthemi (Schrank) & - & 1 \\
\hline Scentless mayweed & Haplothrips leucanthemi (Schrank) * & 19 & \\
\hline \multirow[t]{5}{*}{ Matricaria perforata } & Thrips major Uzel & 8 & \\
\hline & Thrips atratus Haliday & 4 & \\
\hline & Frankliniella intonsa (Trybom) & 3 & \\
\hline & Thrips vulgatissimus Haliday & 2 & \\
\hline & Haplothrips sp. & 1 & \\
\hline Dandelion & Thrips trehernei Priesner * & 31 & \\
\hline \multicolumn{4}{|l|}{ Taraxacum officinale } \\
\hline Creeping buttercup & Frankliniella intonsa (Trybom) * & 7 & \\
\hline \multirow[t]{3}{*}{ Ranunculus repens } & Thrips trehernei Priesner * & 7 & \\
\hline & Thrips major Uzel * & 5 & \\
\hline & Aeolothrips fasciatus (L.) & 1 & \\
\hline White clover & Frankliniella intonsa (Trybom) * & 11 & \\
\hline Trifolium repens & Thrips major Uzel * & 9 & \\
\hline Pineapple weed & Haplothrips leucanthemi (Schrank) * & 6 & \\
\hline \multirow[t]{6}{*}{ Matricaria matricarioides } & Frankliniella intonsa (Trybom) & 2 & \\
\hline & Thrips major Uzel & 2 & \\
\hline & Thrips trehernei Priesner & 2 & \\
\hline & Haplothrips propinquus Bagnall & 1 & \\
\hline & Limothrips denticornis Haliday & 1 & \\
\hline & Thrips tabaci Lindeman & 1 & \\
\hline Pennycress & Thrips trehernei Priesner * & 5 & \\
\hline \multirow[t]{4}{*}{ Thlaspi sp. } & Thrips vulgatissimus Haliday * & 4 & \\
\hline & Aeolothrips fasciatus (L.) & 2 & \\
\hline & Thrips major Uzel & 2 & \\
\hline & Frankliniella intonsa (Trybom) & 1 & \\
\hline Common groundsel & Thrips major Uzel & 3 & \\
\hline \multirow[t]{7}{*}{ Senecio vulgaris } & Limothrips denticornis Haliday & 2 & \\
\hline & Thrips trehernei Priesner & 2 & \\
\hline & Thrips vulgatissimus Haliday & 2 & \\
\hline & Haplothrips aculeatus (Fabricius) & 1 & \\
\hline & Oxythrips bicolor (O.M. Reuter) & 1 & \\
\hline & Thrips atratus Haliday & 1 & \\
\hline & Thrips tabaci Lindeman & 1 & \\
\hline White goosefoot & Thrips vulgatissimus Haliday * & 6 & \\
\hline Chenopodium album & Thrips major Uzel * & 4 & \\
\hline Annual meadow grass & Thrips tabaci Lindeman & 3 & \\
\hline
\end{tabular}


Table 3

(Continued)

\begin{tabular}{lll}
\hline Plant & Thrips species & 2008 \\
\hline Poa annua & Chirothrips manicatus Haliday & 1 \\
& Frankliniella tenuicornis (Uzel) & 1 \\
& Limothrips denticornis Haliday & 1 \\
& Sericothrips bicornis (Karny) & 1 \\
& Thrips atratus Haliday & 1 \\
Shepherd's purse & Thrips major Uzel & 1 \\
Capsella bursa-pastoris & Anaphothrips obscurus (Müller) & 2 \\
& Thrips major Uzel & 2 \\
Field sow-thistle & Haplothrips leucanthemi (Schrank) & 1 \\
Sonchus arvensis & Thrips trehernei Priesner & 1 \\
& Thrips vulgatissimus Haliday & 1 \\
Common knotgrass & Thrips major Uzel & 2 \\
Polygonum aviculare & Aeolothrips fasciatus (L.) & 1 \\
& Thrips trehernei Priesner & 1 \\
\hline
\end{tabular}

Tunnel 2008: Phytoseiid mites

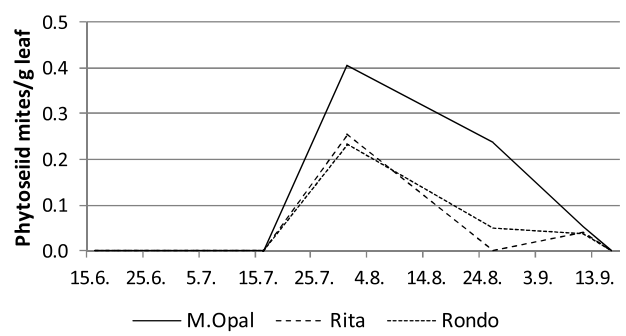

Tunnel 2009: Phytoseiid mites

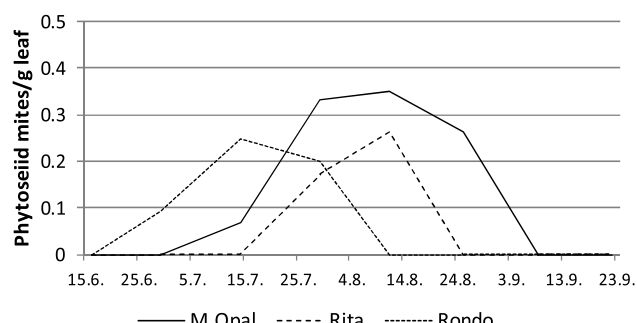

Open field 2008: Phytoseiid mites

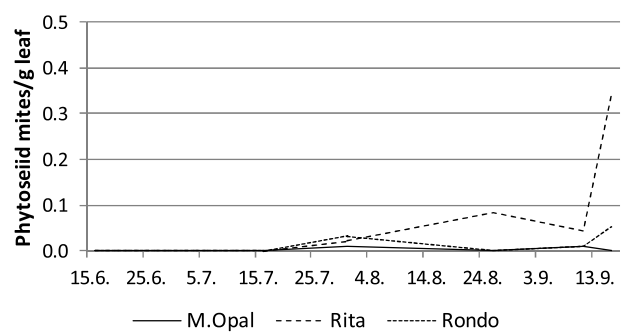

Open field 2009: Phytoseiid mites

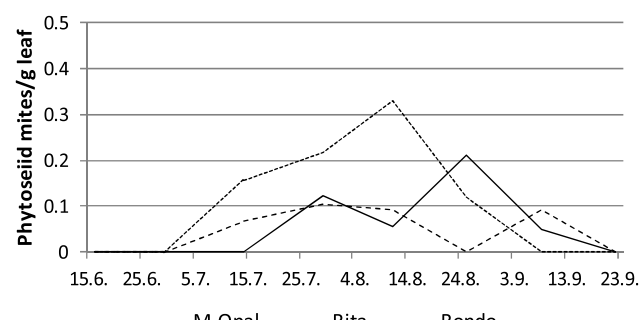

Fig. 8. Phytoseiid mite numbers (motile and eggs) per gram fresh leaf, combined data from leaf and leaflet sampling in 2008 and 2009.

July. In the tunnel, cecidomyiid larvae were no longer evident in late August and September whereas in the open field a slight increase in numbers was noted in September. For the whole leaf samples the number of cecidomyiid larvae correlated closely with the TSSM numbers $\left(r^{2}=0.846, P<0.001\right.$, Spearman Rank Order Correlation). Likewise, predatory staphylinid larvae were found at the end of July in the tunnel and at the end of August in the open field, and the numbers correlated with TSSM $\left(r^{2}=0.382, P=0.006\right)$. The specimens belonged to the genera Feltiella (Diptera: Cecidomyiidae) and Oligota (Coleoptera: Staphylinidae). 
Tunnel 2008: Cecidomyiid larvae

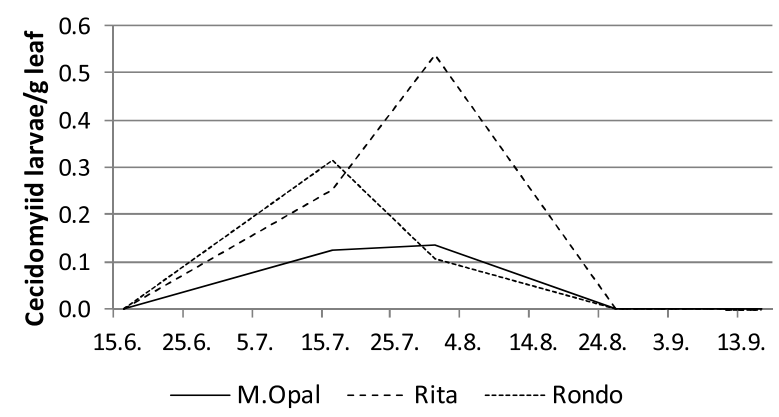

Tunnel 2008: Staphylinid larvae

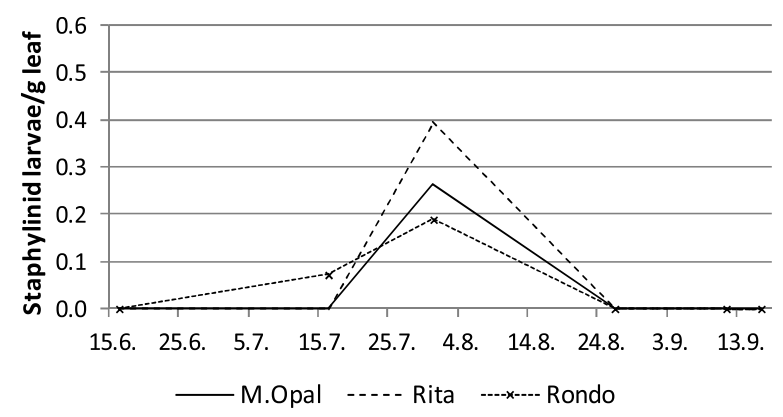

Open field 2008: Cecidomyiid larvae

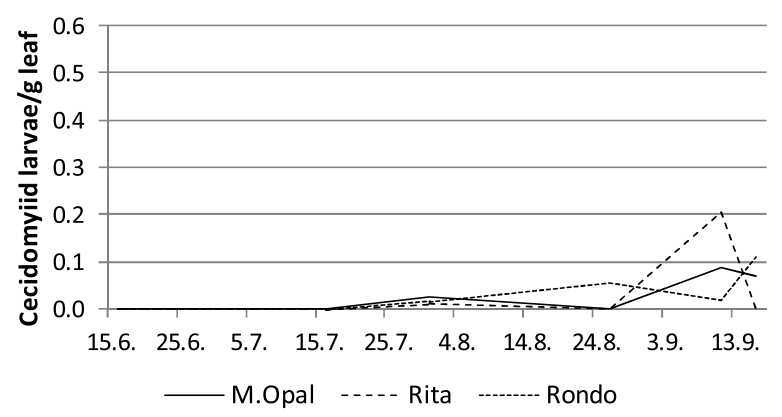

Open field 2008: Staphylinid larvae

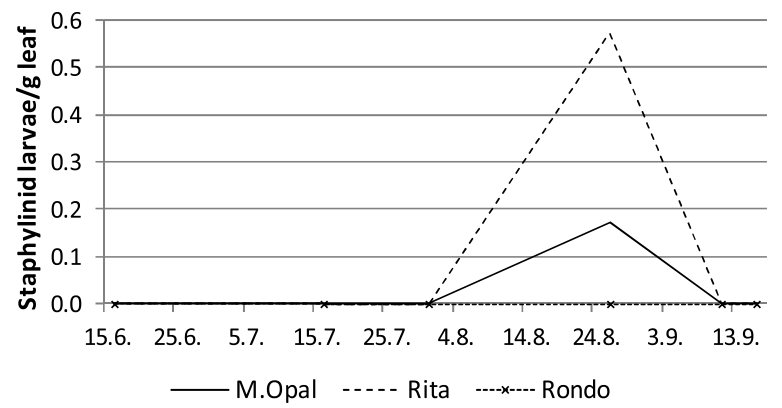

Fig. 9. Predatory cecidomyiid larvae (Feltiella spp.) and predatory staphylinid larvae (Oligota spp.) found in leaf samples 2008.

Both yellow and blue traps caught a few cecidomyiid midges and staphylinid beetles throughout the season. In 2008 only 4 and 4.5, and in 20096 and 7 midges were caught by yellow and blue traps, respectively (the numbers of the twice bigger traps in 2008 divided by 2). Likewise, in 2008, a total of 12 and 10.5, and in 2009, a total of 14 and 13 staphylinid beetles were caught per yellow and blue trap, respectively. High numbers of parasitoid wasps (Hymenoptera) were caught: in 2008, 804 and 583, and in 2009, 1322 and 608 per yellow and blue trap, respectively. The other group of natural enemies, hover flies (Diptera: Syrphidae) were also caught in high numbers: in 2008, 457 and 481, and in 2009, 203 and 364 flies per yellow and blue trap, respectively. Also aphids were numerous in traps: in 2008, 608 and 439, and in 2009, 621 and 45 aphids per trap. Staphylinid beetles and hover flies were slightly more common in the open field in both years, whereas cecidomyiid midges and parasitoid wasps were caught more evenly in the tunnel and open field. Twice as many aphids were caught in the open field than in the tunnel.

\section{Discussion and conclusions}

Biological control of TSSM through releasing the specialist predatory mite $P$. persimilis was supported by naturally occurring cecidomyiid midges present in the field soon after planting in the first year of the experiment. The number of cecidomyiid larvae followed closely the TSSM numbers on the same leaves in the tunnel, showing a clear egg-laying response to the growth of the TSSM population present on the leaves. However, after the peak, the cecidomyiid larvae disappeared from the tunnel whereas in the open field some larvae of the second generation were found. The relatively late releases of $P$. persimilis, starting at the peak of TSSM motiles with a high number of eggs, and the following additional releases, led to the collapse of the TSSM population at the end of August. As $P$. persimilis was still evident when TSSM had almost disappeared at the end of the season we conclude that this predator had the greatest effect on TSSM during the latter half of the season in the tunnel. We also conclude that in spite of the competition for the same resources, $P$. persimilis and cecidomyiid larvae did not interfere with or threaten each other's existence 
in the same field. The same concerns staphylinid beetle larvae, which appeared when TSSM numbers peaked, but disappeared soon after their collapse in the tunnel and appeared again late in the season in the open field. It is possible that the first generation cecidomyiid midges laid eggs in the tunnel during the TSSM egg-laying period and the new generation born in the tunnel laid eggs in the open field where TSSM was still abundant on Rita. In spite of much higher release numbers, the generalist predatory mites $N$. barkeri and $N$. cucumeris were in the minority on the leaf samples, which may be due to their behavior: $N$. cucumeris and $N$. barkeri tend to hide inside folded leaves or flower buds where they seek out thrips, tarsonemid mites and pollen. As the strawberry tarsonemid mite did not occur in the field, the predatory mites were expected to prey mainly on either TSSM or thrips. The initially low population of TSSM in 2009 remained low after the early release of $P$. persimilis. In spite of the low TSSM population, P. persimilis and other phytoseiid mites remained both in the tunnel and in the open field whereas cecidomyiid and staphylinid larvae were absent. The presence of several indigenous phytoseiid mite species, although in low numbers in the field, especially in 2009, indicates that there was a rich diversity of predatory mites in the small experimental area. In perennial strawberry the relevance of naturally occurring predatory mites may be significant in small organic fields where pesticides are not used. $N$. zwoelferi and $N$. reductus are known to occur on strawberry [15, 17] and both prey on spider mites and tarsonemid mites. In conclusion, biological control of TSSM by P. persimilis is practical for both high and low initial populations in the tunnel. In the open field the release of $P$. persimilis was practicable, but could be unnecessary if $N$. cucumeris were to be used for tarsonemid mite control [6]. In the tunnel the release of Feltiella acarisuga (Vallot) may be worth considering as cecidomyiid larvae are known to be efficient mite predators in greenhouses [18].

The thrips species complex varied between years, but the group of the four most common species was apparent. Although the most damaging thrips species, F. occidentalis, did not occur in open field strawberry those species present could cause similar damage. T. major and $F$. intonsa have been reported as pests of strawberry in Switzerland [19], and F. intonsa, T. atratus and T. major in the UK [20]. T. vulgatissimus has not been recorded as a strawberry pest, but is known to prefer white flowers on which to breed [21]. It was present on many weed species also. Thrips fuscipennis Haliday did not occur in the experimental field but is a common thrips species on Rosaceae in Finland, and is known to cause discoloration and malformation of strawberry together with other species [22].

The results show that the TSSM is manageable by biological control both in walk-in tunnels and in open fields. For thrips, more research is needed to explore the role of the species as strawberry pests in northern conditions and the selection of biological control agents.

\section{Acknowledgments}

The authors thank Mr. Jukka Kettunen, Kuopio Natural History Museum, for identification of the thrips.

\section{References}

[1] Wysoki M. Other outdoor crops. In: Helle, W., Sabelis, M. W. Spider Mites: Their Biology, Natural Enemies and Control, Vol. 1B. Elsevier, Amsterdam, 1985, pp. 375-84.

[2] Parikka P, Tuovinen T. Plant protection challenges in strawberry production in northern Europe. In: VII International Strawberry Symposium 2012. ISHS, Beijing, China, 1012. p. 123.

[3] Sances FV, Toscano NC, Lapre LF, Oatman ER, Johnson MW. Spider mites can reduce strawberry yields. Californian Agriculture. 1982;36:15-6.

[4] Easterbrook MA, Fitzgeral JD, Solomon MG. Biological control of strawberry tarsonemid mite Phytonemus pallidus and two-spotted spider mite Tetranychus urticae on strawberry in the UK using species of Neoseiulus (Amblyseius) (Acari: Phytoseiidae). Experimental \& Applied Acarology. 2001;25:25-36.

[5] Tuovinen T, Lindqvist I, Kauppinen S, Kivijärvi P. Integration of biological mite control and conventional insect control in strawberry. Acta Horticulturae. 2009;842:661-4.

[6] Tuovinen T, Lindqvist I. Maintenance of predatory phytoseiid mites for preventive control of strawberry tarsonemid mite Phytonemus pallidus in strawberry plant propagation. Biological Control. 2010;54:119-25.

[7] Koike ST, Zalom FG, Larson, K. Bronzing of strawberry fruit as affected by production practices, environmental factors, and thrips. Hortscience. 2009; 44:1588-93. 
[8] Cross JV, Easterbrook MA, Crook AM, Crook D, Fitzgerald JD, Innocenzi PJ, Jay CN, Solomon MG. Natural enemies and biocontrol of pests of strawberry in Northern and Central Europe. Biocontrol Science and Technology. 2001;11:165-16.

[9] Fitzgerald J, Jay C. Strategies for release of Neoseiulus (Amblyseius) cucumeris to control western flower thrips, Frankliniella occidentalis, in tunnel grown everbearer strawberries. IOBC/wprs Bulletin. 2011;70:97-100.

[10] Brödsgaard HF, Stengaard Hansen L. Effect of Amblyseius cucumeris and Amblyseius barkeri as biological control agents of Thrips tabaci on glasshouse cucumbers. Biocontrol Science and Technology. 1992;2:215-23.

[11] Tuovinen T, Tolonen T. Arthropod biodiversity on conventional and organic strawberry. Acta Horticulturae. 2001;567:663-6.

[12] Tuovinen T, Lindqvist I. Comparison of injuries in everbearing strawberry yield in tunnel and open field conditions. IOBC/wprs Bulletin. 2011;70:197-8.

[13] Tuovinen T, Parikka P. Monitoring strawberry pests and diseases: Practical applications for decision making. Acta Horticulturae. 1997;439:931-40.

[14] Karg W, Huhta V. Taxonomic remarks on Phytoseiidae Berlese (Acari: Mesostigmata), with description of three new species from Finland. International Journal of Acarology. 2009;35:511-520.

[15] Tuovinen T. Identification and occurrence of phytoseiid mites (Gamasina: Phytoseiidae) in Finnish apple plantations and their surroundings. Entomologica Fennica. 1993;4:95-114.

[16] Tuovinen T. Phytoseiid mites on cultivated berries in Finland. In: Kropczynska, D., Boczek and A. Tomczyk (editors). The Acari: Physiological and ecological aspects of Acari-host relationships. Oficyna DABOR, Warszawa. 1995; pp. 240-7.

[17] Tokunova MV, Malov NA. Biological methods of pest control in strawberry. (In Russian). Zaschita Rastenij. 1988;5:37-8.

[18] Yingfang X, Osborne LS, Chen J, McKenzie CL. Functional responses and prey-stage preferences of a predatory gall midge and two predacious mites with twospotted spider mites, Tetranychus urticae, as host. Journal of Insect Science. 2013;13(8):1-12.

[19] Linder C, Antonin P, Mittaz C, Terrettaz R. Thrips on strawberry in western Switzerland: Species, population dynamics and harmfulness. Revue suisse de viticulture, arboriculture, horticulture. 1998;30:161-6.

[20] Buxton JH, Easterbrook MA. Thrips as a probable cause of severe fruit distortion in late-season strawberries. Plant Pathology. 1988;7:278-80.

[21] Moritz G, Morris D, Mound L. ThripsID: Pest thrips of the world: An interactive identification and information system. Australian Centre for International Agricultural Research (ACIAR); 2001. ISBN 186320296, CD.

[22] Alford DV. Pests of fruit crops: A color handbook. Elsevier, London, 2007. 